\title{
DIE RUSSISCHE PARTEISPALTUNG IM URTEIL DER DEUTSCHEN SOZIALDEMOKRATIE
}

I903-1905

(Scbluss)

II

Im Laufe der Herbstwochen des Jahres 1904 wurde das nicht nur für Aussenstehende unentwirrbare Labyrinth der Richtungen unter den russischen Sozialisten mehr und mehr zu einem internationalen Ärgernis. Die chronische Misere der Exilintrigen und Organisationsrivalitäten, die schliesslich nicht allein das gespaltene Lager der russischen Sozialdemokratie zerrütteten, war in ihren grösseren Zusammenhängen erneut während des Amsterdamer Sozialistenkongresses in das Bewusstsein der europäischen Parteien getreten. Anteil daran hatte weniger der Machtkampf zwischen Menschewiki und Bolschewiki, wenngleich das "Internationale Sozialistische Büro” bei der Bestätigung der russischen Mandate auch damit befasst wurde, als vielmehr die Debatten über die Stimmberechtigung der nationalen Fraktionen und Gruppen aus Russland und Österreich-Ungarn. Die nationale Frage musste in Amsterdam als Organisationsproblem der Internationale vor allem deshalb neu durchdacht werden, weil die grossen Parteien erstmals der Gefahr einer Majorisierung durch kleine nationale Gruppen gegenüber zu stehen glaubten. ${ }^{1}$ Mit der gleichberechtigten Aufnahme der russischen Sozialrevolutionäre in die Internationale war in bezug auf Russland vor allem die Stellung des I903 aus der RSDRP ausgeschiedenen jüdischen Arbeiterbundes spruchreif geworden, dem nach seinem Austritt aus der RSDRP (August 1903) ein gesondertes Stimmrecht neben den Sozialdemokraten verweigert worden war. ${ }^{2}$ Die leidenschaftlichen Proteste des

$1 \mathrm{Zu}$ den Bedenken des deutschen Parteivorstandes vgl. Karl Kautsky: Zum Internationalen Kongress, Die Neue Zeit XXII, 2 (1904) S. 577-8 5.

"Unter Berufung auf die Resolution „Uber die Einheit der Partei”, die das Prinzip formulierte, es solle ,in jedem Lande den bürgerlichen Parteien gegenüber nur eine sozialistische Partei" geben (Internationaler Sozialisten-Kongress zu Amsterdam. 14. bis 20. August 1904, Berlin 1904, S. 32), wurde dem jüdischen Arbeiterbund vom I.S.B. empfohlen, sich der Delegation der RSDRP anzuschliessen. Der Antrag des Bund auf „eigene Stimme bei Abstimmungen" wurde am 17. Aug. vom Kongressplenum „mit überwäl- 
Auslandskomitees der Bundisten ${ }^{1}$ gegen diese Regelung hat den Führungsgremien der Sozialistischen Internationale fraglos Sorgen bereitet, zumal der Bund mit Recht auf seine für russische Verhältnisse bewundernswert gefestigten und regen Komitees verweisen konnte. Neben dem jüdischen Arbeiterbund waren in Amsterdam auch ukrainische, ${ }^{2}$ lettische und armenische Gruppen im Gefolge der sozialdemokratischen Delegation aufgetreten und hatten bei den mittel- und westeuropäischen Kongressteilnehmern an der Verhärtung des Eindrucks mitgewirkt, dass das organisatorische Chaos in Russland schwerlich an einen koordinierten Einsatz der Kräfte gegen das autokratische Regime denken liess. Dieses Bild erhielt noch eine weitere Trübung durch den sich immer wieder manifestierenden Antagonismus zwischen der „Polnischen Sozialistischen Partei” (P.P.S.) und der polnischen Sozialdemokratie (SDKPiL). ${ }^{3}$

Was alle diese Verwicklungen so schmerzhaft werden liess, war das durch den fernöstlichen Krieg und die militärischen Niederlagen Petersburgs gesteigerte Russland-Interesse in den europäischen Parteien, das durch die nunmehr erkennbaren Folgeerscheinungen im Inneren des Zarenreiches neue Nahrung erhielt. Mit der im Herbst I 904 einsetzenden Verfassungsbewegung der Semstwo-Kongresse gewann vor allem die Frage nach der Taktik der russischen Sozialisten gegenüber den verschiedenen Richtungen des liberalen Lagers brennende Aktualität. August Bebel hat bereits Mitte September in einem Brief an Axelrod 4 auf diese von den Russen bisher unbeantwortete Frage aufmerksam gemacht und auf die Nützlichkeit „einer gewissen

tigender Mehrheit... ohne Debatte" zurückgewiesen (ibid. S. 14), obwohl der Bund 1903 aus der RSDRP ausgetreten war. Vgl. auch die Argumente Plechanows: V Amsterdame. Mysli i zametki(I), in: Iskra No 74, 20.9/3.10.1904, S. 4.

1 Dic Stcllungnahme des Bundes: K voprosu o predstavitel'stve na meždunarodnom kongresse v Amsterdame, in: Vestnik Bunda No 5, Nov. 1904, S. 2-7; vgl. den Protest gegen die Beschuldigung wegen "nationalistischer Tendenzen": Cleny Internac. Soc. Bjuro protiv Plechanova. Ibid. S. 27 f. Zum Selbstbewusstsein der jüdischen Organisation gegenüber der russischen Partei vgl. Doklad Intern. Soc. Kongressu v Amsterdame. Dejatel'nost' Bunda posle ego V-go s'ezda s ijunja I903 do ijulja 1904 g, Ženeva I 904 , S. 9. - Gurwitsch bat Kautsky am 29. Sept. 1904 um Intervention (Kautsky-Archiv D $\mathrm{XI}, 306)$.

2 Vgl. den Bericht des Central-Komitees der Revolutionären Ukrainischen Partei für den Internationalen sozialistischen Kongress in Amsterdam, Verlag der R.U.P., Genf r 904, I6 S. 3 So sprach der offizielle Bericht der SDKPiL an den Amsterdamer Kongress, der von Rosa Luxemburg vorgelcgt wurde, vom „endgiltigen Bankerott” der Versuche der PPS, „den Leichnam des Nationalismus durch die künstliche und abnorme Verquickung mit der modernen lebensfrischen Arbeiterbewegung zu galvanisieren..." (Über die polnische sozialdemokratische Bewegung in Russisch-Polen und Littauen I900-I 904 [Berlin 1904], S. 8.)

4 Bebel an Axelrod, 13. Sept. 1904 (Abschrift im Axelrod-Archiv). 
Cooperation mit den Liberalen" hingewiesen. Da Russland vermutlich „über ein mehr oder weniger lange dauerndes liberales Regime” nicht hinwegkomme, verbiete es ,schon die Klugheit, sich mit diesen im voraus tödtlich $z u$ verfeinden". ${ }^{1}$ Die im Spätherbst eingeleiteten Einigungsversuche von deutscher Seite waren denn auch ausgelöst von dem Bestreben, der in Gang gekommenen oppositionellen Bewegung gegen die gefährdete Autokratie eine aktionsfähige sozialistische Einheitsfront zur Seite zu setzen. Die Spaltung der russischen Sozialdemokraten erwies sich für die deutsche Parteispitze dabei als Teilproblem eines grösseren Fragenkomplexes, der zumindest die nichtrussischen sozialdemokratischen Parteien und Gruppen, vor allem den jüdischen Arbeiterbund und die Sozialdemokratie Polens und Litauens, mit einschloss. Als Bebel am 21. Oktober Axelrod den Gedanken einer Einigungskonferenz zum ersten Male entwickelte, ${ }^{2}$ war mit Rücksicht auf die Ressentiments der russischen Sozialdemokraten die Mitwirkung der Sozialrevolutionäre noch nicht in Betracht gezogen worden. Ebenso wenig wurde an eine Beteiligung der P.P.S. gedacht, ein Hinweis darauf, dass die leidenschaftliche Aufklärungsarbeit Rosa Luxemburgs in der deutschen Partei und die deutsch-polnischen Organisationsdifferenzen im preussischen Teilgebiet ${ }^{3}$ ihre Wirkung getan hatten.

Bebel schlug vor, diejenigen „russischen sozialistischen Fraktionen” auf einer Konferenz zusammenzufassen, „die sich so nahe stehen, dass eine gemeinsame Cooperation möglich" sei. Er verstehe darunter neben dem Kreis um die Iskra ,die Anhänger Lenins, [den] jüdische[n] Bund, die Letten und die Polen". Voraussetzung sei jedoch, dass ,sich in erster Linie" die Freunde Axelrods zu diesem Plane bekennen, da er ,ein gänzlich aussichtsloses Unternehmen" nicht beginnen wolle.4 Für den Fortgang der Gespräche war wesentlich, dass Bebel trotz der Bedenken der Menschewiki auch weiterhin an eine Beteiligung Lenins gedacht hat. Als Axelrod Anfang November 1904 die Absicht äusserte, nach Berlin zu reisen, ${ }^{5}$ schlug ihm Bebel vor, die vorgesehene Konferenz gleich mit diesem Besuch zu verbinden, wobei es wichtig sei, „dass auch Lenin rechtzeitig unterrichtet” werde. ${ }^{6}$ Das nunmehr

1 Ibid.

2 Bebel an Axelrod, 21. Okt. 1904 (Axelrod-Archiv).

3 Vgl. dazu: Protokoll über die Verhandlungen des Parteitages der Sozialdemokratischen Partei Deutschlands abgehalten zu Jena vom 17. bis 23. Sept. 1905, Berlin 1905. Ferner Estera Golde: Zur polnischen Parteifrage, in: Die Neue Zeit XXIII, 2 ( 1 gos) S. 737-40.

4 Bebel an Axelrod, 21. Okt. 1904.

5 Kautsky hat Axelrod am 4. Nov. I 904 mitgeteilt, Bebel sei bereit, ihn zu empfangen (Brief im Axelrod-Archiv).

${ }^{6}$ Bebel an Axelrod, 5. Nov. 1904 (Abschrift im Axelrod-Archiv). 
angesprochene Vorhaben scheint indessen bis Mitte Dezember nicht vorangekommen zu sein, vermutlich wegen der Abneigung der Menschewiki, sich mit Lenin als Vertreter einer gleichberechtigten Fraktion zusammenzusetzen. Diese Annahme macht ein Brief Bebels vom 15. Dezember wahrscheinlich, mit dem er Axelrod davon in Kenntnis setzte, dass „der Vorschlag einer Aussöhnung mit den auswärtigen Freunden volle Zustimmung" finde, der ,innere Conflict” dagegen „unabhängig davon, als ein selbständiger Gegenstand" behandelt werden müsse. „Wollten wir beide Angelegenheiten vereinigen oder die Regelung des häuslichen Streites als absolute Voraussetzung erklären, so würde sich dadurch die Realisierung des anderen Vorschlages in die Länge ziehen”. Das aber wäre „sehr unerwünscht". ${ }^{1}$

Mit der Reise Bebels nach Zürich, wo er sich vom I9. Dezember bis Anfang Januar bei Tochter und Schwiegersohn (Dr. med. Simon) aufgehalten hat, ${ }^{2}$ trat die Planung endlich in ein konkreteres Stadium. Kautsky riet seinem Freunde Axelrod am i9. Dezember, er möge sich in Zürich mit Bebel verständigen. Er (Kautsky) denke an eine Verbindung der vorgesehenen Konferenz mit der für den Is. Januar I90s nach Brüssel einberufenen Sitzung des Internationalen Sozialistischen Büros. ${ }^{3}$ Dort seien dann ohnehin ,die meisten der Leute, um die es sich handelt" beisammen; in jedem Falle aber könne in Brüssel eine „erste vertrauliche Besprechung" stattfinden, bei der man sich „über die wichtigsten Fragen ausspricht und orientiert". ${ }^{4}$ Kautsky drängte nicht ohne Grund. Die Frage eines Zusammenschlusses der sozialdemokratischen Organisationen war mittlerweile umso dringlicher geworden, als zur gleichen Zeit in Paris ein Aktionsbündnis zwischen dem liberalen „Befreiungsbund” (Sojuz Osvoboždenija), der polnischen „Nationalliga” (Liga Narodowa) und der finnischen „Partei der aktiven Resistance" einerseits und den Zentralinstitutionen der P.P.S., der russischen Sozialrevolutionäre, sowie einigen sozialis-

1 Bebcl an Axelrod, I 5. Dez. I 904 (Abschrift im Axelrod-Archiv). Der „innere Conflict” meint dic Krise innerhalb der RSDRP, die „Aussöhnung mit den auswärtigen Freunden” den Plan cines Aktionsabkommens mit den im Brief vom 21. Okt. 1904 genannten Gruppen.

2 Die Daticrung für die Abreise nach Zürich ergibt sich aus dem Briefe Kautskys an Axclrod vom 19. Dez. I904 (Axelrod-Archiv). Der letzte Brief Bebels aus Zürich an V. Adler stammt vom 4. Jan. I9o5, scin erster Brief aus Berlin vom 8. Jan. (V. Adler, Briefwechsel mit August Bebcl und Karl Kautsky, Wicn 1955, S. 452). Vgl. auch Perepiska G. V. Plechanova, a.a.O.T. II, S. 206.

a Vgl. den Bericht über die Sitzung des Büros: Vorwärts No 15, 18.1.I905, I. Beilage. Das I.S.B. hat an I5. Jan. Igos im Anschluss an Amsterdam die Fragen des Abstimmungsmodus erörtert.

4 Kautsky an Axelrod, i 9. Dez. 1904 (Axelrod-Archiv). 
tischen Gruppen der „Fremdvölker” zustande gekommen war. ${ }^{1}$ Diesem „Block der oppositionellen und revolutionären Parteien”, der bereits nach der Ermordung Plehwes (28. Juli 1904) von finnischer Seite angeregt worden war, ${ }^{2}$ hatten sich schon im Frühstadium der Gespräche die russischen, jüdischen und polnischen Sozialdemokraten versagt. Während des Amsterdamer Kongresses hatten sie eine Ablehnung formuliert, welche die Aufforderung zur Mitwirkung mit dem Argument zurückwies, dass die Mehrzahl der präsumptiven Teilnehmer dem Klassenkampfgedanken fremd gegenüberstünde und dieses „von Abenteurertum nicht freie" Unternehmen mit der Zielsetzung der Sozialdemokratie unvereinbar sei. ${ }^{3}$ Kautsky hat Axelrod in seinem Brief vom 19. Dezember - vermutlich unter dem Eindruck der eben bekannt gewordenen Pariser Konferenzbeschlüsse - angeraten, in der deutschen Parteipresse die sozialdemokratische Haltung „gegenüber dem liberalen Block... (wie) überhaupt Euere Taktik in Russland” auseinanderzusetzen. Die „Bewegung in Russland” sei „augenblicklich das wichtigste Faktum des internationalen Sozialismus" und ihr Verständnis für die deutschen Genossen „dringend notwendig". Offensichtlich hat die kritische Aufnahme, die die Abstinenz der Sozialdemokratie Russlands anlässlich des Pariser Aktionsbündnisses beim "Vorwärts”, der Wiener „Arbeiter-Zeitung” und der „Humanité” gefunden hatte, ${ }^{5}$ ein zusätzliches Motiv für das Drängen Kautskys gebildet.

Die Einigung der Sozialdemokraten des Zarenreiches geriet zum

1 Die Resolutionen der Konferenz des sogenannten „Pariser Blocks”: Revoljucionnaja Rossija No 56, 5./18.12.1904, S. 1-8; vgl. auch: Nekotorye itogi Parižskoj konferencii, ibid. No 61, 15./28.3.1905, S. 2-6.

2 Zur finnischen Initiative vgl. Konni Zilliacus: Das revolutionäre Russland. Eine Schilderung des Ursprungs und der Entwicklung der revolutionären Bewegung in Russland, Frankfurt/M. I905, S. 369 f. Ferner: Martow an Axelrod, 3. Aug. I904 (Pis'ma P. B. Axel'roda, a.a.O. S. 108).

3 Text der Absage, angenommen durch den Parteirat der RSDRP, das Auslandskomitee des Bund, durch SDKPiL, P.P.S- Proletariat, Revolutionäre Ukrainische Partei, Lettische Sozialdem. Arbeiterpartei: Iskra No 79, 1./13.12. 1904, S. 4; zur Beurteilung der Konferenz s, den Leitartikel in der gleichen No der Iskra: Ob'edinenie buržuaznoj demokratii (S. I-4). Ferner: O. B. Szmidt: Socjaldemokracja Królestwa Polskicgo i Litwy. Materialy i dokumenty, 1883-1904, T. I, Moskva 1934, S. 568-75.

4 Kautsky an Axclrod, 19. Dez. I904 (Axclrod-Archiv).

5 Vgl. die Polemik um die Stellung der RSDRP zur Pariser Konferenz: Vorwärts, 22.1 2.1904 und Iskra No 82, 1./13.1. 1905. - Wenn man solche Besprechungen grundsätzlich verwerfe, antwortete der „Vorwärts” (No 17, 20.1.1905, I. Beilage, S. 3), „so verzichtct man von vornhercin auf die Einleitung und planmässigc Durchführung ciner grosszügigen gemeinsamen Aktion. Wir möchten... hoffen, dass dic russische Sozialdemokratie nunmehr auch ihrerseits kein Mittel unversucht lässt, um möglichst schnell alle revolutionären und oppositionellen Kräfte zu eincm gemcinsamen planmässigen Vorgehen gegen den Zarismus zusammenzufassen". 
Jahresende hin mehr und mehr unter den Druck der öffentlichen Meinung des sozialistischen Europas. Hinzu kam, dass sich jetzt auch Viktor Adler in die „Russen-Einigungs-Aktion” einschaltete und den weiteren Planungen seinen Stempel aufzudrücken versuchte. Der österreichische Parteiführer, der seit den neunziger Jahren Rosa Luxemburg ebenso kritisch gegenüber stand wie Plechanow, mit dem er letztmalig in Amsterdam die Klingen gekreuzt hatte, ${ }^{1}$ war von der Unfehlbarkeit der Menschewiki weit weniger überzeugt als der deutsche Parteivorstand. Plechanow, so schrieb er am 26. Dezember an Bebel nach Zürich, mache eine ,sehr schlechte Politik im kritischsten Moment”, er gehöre zu den „Gelehrten”, die ihre „künftigen Kritiker mehr fürchten als die Folgen ihres Tuns" und so zu "Gefangenen der Dinge" würden, „die sie einmal niedergeschrieben haben”:

„Alle Kräfte sollten jetzt entfesselt werden u[nd] ich habe den Eindruck, dass er sie lähmt durch Doktrinarismus und Buchstabenreiterei.... Für mich liegt der Schwerpunkt alles Interesses jetzt in Russland, ich brenne einfach vor Spannung $u[n d]$ meine, dass dort unser aller Los für lange wenn nicht entschieden so doch entscheidend beeinflusst wird. Und da streiten sich die Leute um Worte herum!" 2

Adler bat Bebel dringend, ihn auf dem Laufenden zu halten und schlug wie Kautsky vor, Brüssel als Tagungsort für die „RussenSache" vorzusehen. Bebel antwortete am 28. Dezember: Auch er sei der Meinung, ,dass der Versuch gemacht werden müsse, die streitenden Parteien zusammenzubringen", zumal „alles worüber man streitet und uneinig ist... doch nur Quark" sei, „gegenüber dem was praktisch auf dem Spiele steht und was gearbeitet werden soll. Zeigen sich die Leute jetzt nicht der Situation gewachsen dann handeln sie unverantwortlich..." 3

Inzwischen war Bebel in seinen Gesprächen mit Axelrod auf eine merkwürdige Zurückhaltung gestossen. Axelrod sage, so berichtete er Adler, „halb ja, halb nein. Initiative will er nicht ergreifen”, obwohl er bereit sei, „mit seinen Leuten zu kommen, wenn ich eine solche veranlasste".4 Ein Brief Bebels an Axelrod vom 29. Dezember lässt deutlich werden, dass der deutsche Parteivorsitzende bei seinen Vorbereitungen auf die Mitwirkung Axelrods nicht verzichten wollte, zumal er sich ohne ihn schwerlich im organisatorischen und per-

1 Zum Zusammenstoss zwischen V. Adler und Plechanow vgl. Internationaler Sozialisten-Kongress zu Amsterdam, a.a.O.S.70, sowic Plechanow in: Iskra No 75, 5./18. 10.1904, S. 2-5.

2 V. Adler, Briefwechsel S. 445 .

3 Ibid. S. $44^{6}$.

4 Bebel an Adler, 28. Dez. I904, ibid. 
sonellen Gestrüpp des osteuropäischen Exils zurechtgefunden hätte. Bebel überliess Axelrod die Auswahl der Teilnehmer und bat ihn, er möge umgehend Schritte einleiten, „damit eine entsprechende Einladung und eine möglichst vollständige Vertretung der Beteiligten" erfolgen könne. Axelrod wisse schliesslich „am besten auf wen es ankommt und wer dabei unter allen Umständen vertreten sein muss". Falls Brüssel als Tagungsort nicht annehmbar sei, so erkläre er sich zusammen mit Adler bereit, eine Konferenz im Januar in einer süddeutschen Stadt abzuhalten. In jedem Falle aber müsse die Konferenz „bald stattfinden”, die „Vorgänge in R[ussland] [machen ein] gemeinsames Handeln zur Notwendigkeit". ${ }^{1}$

Inzwischen war auch Adler durch Axelrods Sohn (Sascha) eingehender von der „Russengeschichte” informiert worden. Ihm sei dabei klar geworden, so schrieb er Bebel am Neujahrstage, dass es für die Menschewiki „nur wesentlich um den inneren Streit innerhalb der 'Sozialdemokratischen Partei' " gehe, um ,den Streit zwischen 'Iskra', will sagen Plechanow und Axelrod einerseits und dem übergeschnappten Lenin andererseits". Im besten Falle käme noch die Vereinigung mit dem jüdischen Arbeiterbund hinzu, während die „kleinen nationalen Fraktionen Letten, Georgier, die polnische Rosa-[Luxemburg-] Partei... Bagatellen" seien. Stattdessen regte Adler „eine noch so lose Vereinigung mit den 'Revolutionären Sozialisten' (samt ihrer Terroristengruppe)" an und „vor allem mit der 'P.P.S.', der Polnischen Sozialistenpartei (der grossen, nicht der Rosaisten)”, was „politisch von grösster Wichtigkeit" wäre. Erneut schlug Adler Brüssel als Tagungsort vor, diesmal mit der Begründung, dass ,,dort auch die 'Bundisten' und die So[zialisten]-Revol[utionäre] kommen", und sich während der Sitzung des I.S.B. Diskussionen über diese Frage ohnehin ergeben würden. In bezug auf die Zurückhaltung Axelrods, die Bebel als "merkwürdig" vermerkt hatte, sah Adler durchaus richtig, wenn er schrieb, dass dieser „nur von einer Konferenz, die von dritter Seite, also von Dir [Bebel] einberufen ist", etwas erhoffe und den Schein vermeiden wolle, ,als wäre sie eigentlich von ihm veranstaltet”. „Es scheint”, so resümierte Adler, „dass er [Axelrod] es für gefährlich hält, allzu sehnsüchtig nach dem Frieden auszusehen". ${ }^{2}$

Als Bebel die Anregungen Adlers an Axelrod weitergab, wollte sich dieser ,weder auf eine Einladung der Rev. Soc. noch der P.P.S.”

1 Bebel an Axcltod, 29. Dez. I904 (Abschrift im Axclrod-Archiv).

2 Adler an Bebel, I. Jan. I905 (V. Adler, Briefwechsel, S. 450 f.). Alexander Axeirod schrieb zur gleichen Zeit aus Wien seinem Vater nach Zürich, Adler befinde sich in einem Zustand „fieberhafter Aufregung wegen der Ereignisse in Russland”. (Perepiska Plechanova, a.a.O. T. II, S. 207.) 
einlassen. „Die Gründe gegen letztere”, so versicherte Bebel am 4. Januar seinem Wiener Freunde, halte er für „besonders fadenscheinig". Auch habe Axelrod abgelehnt, die Konferenz in Brüssel abzuhalten, weil sie dann ,über den von ihm und seinen Leuten für nötig erachteten Rahmen hinausgehe". ${ }^{2}$ Bebel, der diese Bedenken nicht auszuräumen vermochte, vereinbarte nunmehr mit Axelrod die Einberufung der Konferenz für den I8. Januar nach Zürich. Adler wurde gebeten, die Einladungen an die polnische Partei „Proletariat”, die „Russische Ukrainische Partei” (Lemberg) und an die „Sozialdemokratische Partei von russisch Polen und Litauen”, deren Vertreter Warski-Warszawski in Krakau sass, ergehen zu lassen. Keine Fraktion sollte mehr als drei Delegierte entsenden. ${ }^{3}$

Dieses Zwischenergebnis der Vorbereitungsarbeiten wurde indessen wenige Tage später wieder fragwürdig. Unmittelbar vor seiner Rückreise nach Berlin hatte Bebel zur Kenntnis nehmen müssen, dass Axelrod ,auch von der Einladung Lenins nichts wissen" wolle. Axelrod habe ihm, so unterrichtete er Adler am 8. Januar, „über L[enin] Dinge mit[geteilt], die diese Abneigung erklären lassen", wobei er (Bebel) allerdings der Meinung sei, man müsse dann auch "gegen L[enin] vorgehen".4 Axelrod wurde von Bebel am selben Tage nochmals darauf aufmerksam gemacht, Adler sei ,sehr unzufrieden", dass die P.P.S., deren Bedeutung die der Letten und Ukrainer bei weitem übersteige, nicht eingeladen würde; auch er teile die Auffassung Adlers, dass die Polen beteiligt werden müssten, „soll bei der Sache etwas herauskommen". 5

Kautsky, der von Bebel über die Züricher Absichten ins Bild gesetzt worden war ${ }^{6}$, wandte sich nunmehr seinerseits an Axelrod. Am 10. Januar protestierte er sowohl gegen den Plan, die Zusammenkunft in Zürich statt in Brüssel abzuhalten, was eine ungerechtfertigte „Verschwendung von Zeit, Kraft und Geld" bedeute, als auch gegen den von Axelrod betriebenen Ausschluss Lenins:

„Dass Ihr Lenin nicht zuzieht, begreife ich nicht. Aus formellen Gründen mag das gerechtfertigt sein, aber so formell darf man die

1 Bebcl an Adler, 4. Jan. I 905 (ibid. S.452).

2 Ibid.

3 Ibid. Vgl. Axelrod an Plechanow, 6. Jan. Igos (Perepiska, T. II, S. 206 f.); der Brief geht u.a. auf die Spannungen mit den Bundisten ein, wobei Axclrod versucht hat, mässigend auf $P$. einzuwirken.

4 Bebel an Adler, 8. Jan. igos (ibid. S. 452 f.). Dazu Plechanow an Axelrod, 13. Jan. 1905 (Perepiska, T. II, S. 207f.).

5 Bebel an Axelrod, 8. Jan. 1905 (Abschrift im Axelrod-Archiv).

- Auch Adrer hatte sich an Kautsky mit der Bitte gewandt, er möge an der vorgesehenen Konferenz in Zürich teilnehmen (Brief vom 9. Jan. rgos, V. Adler, Briefwechsel, S.453). 
Sache doch nicht auffassen. Vom politischen Standpunkt scheint mir der Ausschluss [Lenins] von der Einladung ein Fehler. Mag er formell keine besondere Organisation repräsentieren, er hat einen starken Anhang und Eure Aufgabe ist es, entweder ihn samt seinem Anhang zu gewinnen oder den Anhang von ihm loszulösen, ihn zu isolieren. Weder das eine noch das andere geschieht, wenn man ihn ignoriert. In der jetzigen Situation, die eine Zusammenfassung aller revolutionären Kräfte erfordert, wäre es meines Erachtens Eure Aufgabe, in der Versöhnlichkeit bis an die äusserste Grenze zu gehen. Erweist sich dann eine Einigung [als] unmöglich, dann hat sich Lenin in's Unrecht gesetzt, dann könnt Ihr mit ganz anderer Kraft und ganz anderem Erfolg gegen ihn vorgehen als jetzt, wo Euer Conflict fast nur als ein reiner Competenzstreit erscheint, bei dem auch wieder der formalistische Charakter in den Vordergrund tritt. Ihr seid doch keine Bureaukraten sondern Revolutionäre." 1

Auch Bebel sah sich nach seiner Rückkehr von Berlin von zwei Seiten her in die Zange genommen. Während Kautsky offensichtlich mit den gleichen Argumenten sowohl gegen Brüssel als Tagungsort wie gegen die Ausschaltung Lenins Front machte, legte nunmehr auch Rosa Luxemburg mit der ihr zu Gebote stehenden Leidenschaftlichkeit gegen den Einigungsplan in der vorgesehenen Form Verwahrung ein. Die Beweggründe für ihren Widerstand hat sie am 9. Januar in einem scharfen Schreiben an Axelrod dargelegt, das den Umfang ihrer Erregung bildhaft werden lässt. ${ }^{2}$ Besonders erbittert war sie von der Tatsache, dass Axelrod und Bebel sich auf die Mitwirkung ihres alten Opponenten Viktor Adler eingelassen hatten. Sie könne Adler, so erklärte sie, ,in der Rolle eines unparteiischen Vermittlers" nicht akzeptieren; dieser „Spezialist eines universalen Maklertums [vsemirnago maklerstva] im Interesse des Opportunismus" trete "auf allen internationalen Konferenzen als Schirmherr der P.P.S." auf und stehe auf einem uns "direkt entgegengesetzten Standpunkt". Sie werde am I 5 . Januar in Brüssel, ,in aller Form" darauf bestehen, dass Adler ausscheide. Rosa Luxemburgs polnische Empfindlichkeiten, die sowohl durch Adler als auch durch die beabsichtigte Einladung der Gruppe „Proletariat” 3 angerührt wurden, waren es nicht allein, die 1 Kautsky an Axclrod, Io. Jan. I90s (Axelrod-Archiv).

2 Das acht Folio-Seiten umfassende Schreiben Rosa Luxemburgs vom 9. Jan. 1905 (in russischer Sprache) befindet sich im Axelrod-Archiv. Die Existenz dieses Briefes ist seit 1925 bekannt (vgl. Perepiska G. V. Plechanova, T. I, S. 204), in vollem Wortlaut erstmals in: Social'demokratičeskoe dviženie v Rossii T. I, Moskva-Leningrad 1928, S. 1 50-52. 3 Die Gruppe „Proletariat” (L. Kulczycki), die sich zum individuellen Terror bekannte, wurde von der SDKPiL als eine polnische Filiale der russischen Sozialrevolutionäre bekämpft. 
ihren Zorn hervorgerufen hatten. Nicht minder heftig warf sie Axelrod vor, ,wie und warum" er sich mit der Einberufung der Konferenz habe einverstanden erklären können, da ihm doch klar geworden sein müsse, „dass die Deutschen nicht die leiseste Vorstellung von der jetzigen 'Taktik der Russen in bezug auf den 'liberalen Block' haben". Sie habe Bebel ,so wenig informiert" gefunden, dass dieser sich sogar willens zeige, dem "luftigsten Abkommen" zuzustimmen, ohne sich dabei an ,jeglichen föderalistischen Tendenzen und dem Separatismus des [jüdischen] Bund" zu stossen. Auf diesem Wege werde auf der Konferenz jene „fürchterliche Kopflosigkeit” ihre Fortsetzung finden, die bei den Vorbereitungen geherrscht habe. Da die deutschen Genossen ,überhaupt noch nicht" über die russischen Angelegenheiten orientiert seien, könne das Treffen „die Sache der Einigung nur ernstlich erschweren und gefährden":

„Teilnahme und Hilfe von Ausländern sind nur insoweit gut, als sie uns wirklich helfen, unsere Ansichten und Wünsche zu verwirklichen; soweit sie uns aus Unverstand von dem von uns gewünschten Standpunkt an den Haaren wegziehen wollen, ist ihre Teilnahme ein lachhaftes Hindernis [smešnoj pomechoj], demgegenüber man im Stande sein muss, jene unbeirrbare Festigkeit zu zeigen, mit der zum Beispiel die Guesdisten ihre Positionen verteidigt haben, zu einer Zeit, da die ganze sozialistische Welt den Ruhm von Jaurès verkündet hat". ${ }^{1}$

Während Rosa Luxemburg noch ihre ganze Beredtsamkeit einsetzte, um Axelrod zu einer Intervention bei Bebel gegen die in Zürich vereinbarte Konferenz zu veranlassen, ${ }^{2}$ vertraute Bebel unter dem Eindruck der in Berlin aufgetretenen Schwierigkeiten Adler an, es drohe „eine solche Confusion zu entstehen", dass er ,einstweilen” die Einladungen nicht absenden werde. ${ }^{3}$ Adler selbst kam zu spät, als er noch am ro. Januar Kautsky um ,absolute Diskretion” bat, da er vermeiden möchte, "dass Rosa irgendeine Verschwörung gegen ihre 'Partei' wittert". "Die streitbare Sachwalterin ihrer polnischen Freunde hatte es bereits durchgesetzt, dass Bebel die Bataille abblasen liess. Am I I. Januar schrieb dieser resignierend nach Wien, dass der Einigungsversuch wegen der Verwirrung um die „Aufgaben der Conferenz und den Kreis der Einzuladenden..." unterbleiben müsse. ${ }^{5}$ In der entsprechenden Mitteilung an Axelrod gestand Bebel nunmehr auch die

1 R. Luxemburg an Axcltod, 9. Jan. I 909 (Axelrod-Archiv).

2 Ibid. - R. Luxemburg bat Axelrod nachdrücklich, er möge Bebel telegraphisch um Verschiebung der Konferenz bitten.

${ }^{3}$ Bebel an Adler (Postkarte), 9. Jan. 1905 (V. Adler, Briefwechsel, S. 454).

4 Adler an Kautsky, 10. Jan. I90s (ibid.).

5 Bebel an Adler, I I. Jan. 1905 (ibid.). 
Tatsache ein, dass ihn zu diesem Entschluss „namentlich... eine Besprechung gebracht" habe, die er "mit der Genossin Luxemburg hatte”. ${ }^{1}$

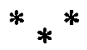

Es konnte nicht ausbleiben, dass das Scheitern des Einigungsversuchs eine weiterwirkende Verstimmung hinterliess. Vor allem Bebel wird aus dieser ersten, intimeren Begegnung mit dem fraktionellen und personellen Durcheinander im osteuropäischen Exil schmerzliche Erfahrungen gezogen haben. So waren in Berlin und Wien die Hoffnungen auf einen bestimmenden Eingriff der sozialdemokratischen Organisationen äusserst gedämpft, als sich nach dem Petersburger Blutsonntag (22. Januar) eine Welle spontaner Aktionen der Arbeiterschaft über Russland hin ausbreitete. Diese skeptische Zurückhaltung der Parteiöffentlichkeit Europas suchte und fand indessen Ausgleich in der Begeisterung für die ,elementaren und mit Naturgewalt hervorbrechenden" Eruptionen der Massenerregung, die Zeugnis ablegten von der ,ungebrochenen Kraft des russischen Volkes”.2 Die Gestalt des Popen Gapon, der an die „Volksmänner der Bauernkriege” gemahne, ${ }^{3}$ die terroristischen Akte „einzelner Helden”, die sich „in die Speere der Tyrannei werfen", 4 zogen die Blicke der europäischen Bruderparteien ungleich stärker auf sich als aus Genf nach Berlin oder Wien geschickte Resolutionen sozialdemokratischer Exilliteraten. In diesen Tagen unklarer Erwartung widersprach die Wiener „Arbeiter-Zeitung” Viktor Adlers der Auffassung nicht, dass „das ganze russische Volk... hinter den Liberalen" stehe; kommentarlos gab das Blatt Äusserungen aus Petersburg wieder, in denen es hiess: „Besässe Russland fünf entschlossene und einander völlig ergebene Männer, so wäre es heute für sie ein Leichtes, sich als provisorische Regierung zu konstituieren. Die ganze Nation würde sich ihnen anschliessen..." Diese entschlossenen Männer schien man freilich nicht in den Reihen der russischen Sozialdemokratie zu suchen. Die allseitige Bewunderung für den "sonderbaren Mann" im Priesterkleide, dessen Wiedererscheinen die Arbeiter erwarteten, ${ }^{7}$ oder die Aufwertung des individuellen Terrors als „Recht des Volksgewissens", 8 als „Werkzeug... der vernünftigen revolutionären Poli-

1 Bebel an Axelrod, 12. Jan. I 905 (Abschrift im Axelrod-Archiv).

$2 \mathrm{Vgl}$. Vorwärts No 42 , I 8.2.1905, S. I.

3 Arbeiter-Zeitung (Wien) No 22, 22.1.1905, S. I.

4 Vorwärts No 42, 18.2.1905, S. 1.

5 Arbeiter-Zeitung (Wien) No 27, 27.1.1905 S. 3.

6 Ibid.

7 Ibid. No 50, 19.2.1905.

8 Vorwärts No 42, 18.2.1905, S. 1 . 
tik", ${ }^{1}$ waren Symptome für das Ausmass des Prestigeverlustes, den die zerrissene Partei der russischen Sozialdemokraten in diesen Wochen erlitten hatte. Demgegenüber stieg das Ansehen der Sozialrevolutionäre, besonders nach der Ermordung des Grossfürsten Sergej durch Kalajew (1 7. Februar), während für die revolutionäre Entwicklung in Russisch-Polen von Wien her die Rolle der P.P.S. in den Vordergrund geschoben wurde. ${ }^{2}$ Kautsky hatte schon Anfang Februar Mühe, die Spalten der „Neuen Zeit” für Stimmen zu verschliessen, die - wie der Theoretiker der P.P.S., Michael Lusnia (Kazimierz KellezKraus) - mit der These aufwarteten, dass „Polen sicher, vielleicht aber nicht Russland für die Demokratie reif" sei. ${ }^{3}$

In dieser Situation entschloss sich August Bebel, die abgerissenen Fäden seiner Befriedungsaktion noch einmal aufzunehmen, jetzt allerdings mit der begrenzteren Zielsetzung eines Burgfriedens zwischen Lenin und dessen Gegnern. Die zugänglichen Quellen lassen nicht eindeutig erkennen, ob dieser Versuch noch während der Sitzung des I.S.B. in Brüssel (1 5 . Januar) mit dem dort anwesenden Axelrod abgesprochen worden war; alle Anzeichen sprechen jedoch dafür. ${ }^{4}$ Am

1 Arbeiter-Zeitung (Wien) No 50, 19.2.1905, S. I.

2 So erschien in der Wiener Arbeiter-Zeitung z.B. ein Fortsetzungsbericht aus der Feder von Josef Pilsudski: Das unterirdische Polen. Tatsachen und Erfahrungen aus den letzten zchn Jahren (No 64-75, 5.-I9.3.1905). Zur Würdigung der Rolle der PPS vgl. auch M. Lusnia: Die Polnische sozialistische Partei, in: Arbeiter-Zeitung No 85, 26.3.1905, S. 4-5.

${ }^{3}$ Kautsky an Lusnia, 4. Febr. I9os (Kautsky-Archiv): „Werther Genosse, ich bedauere, Ihren Artikel nicht acceptieren zu können. Er würde eine Menge Streitfragen aufrollen, die zu lösen dic deutsche Sozialdemokratie nicht berufen ist, so lange noch die Möglichkeit vorhanden ist, dass die Sozialdemokraten Russlands ihre Streitigkeiten unter sich ausmachen und zu einer Einigung gelangen. Überdies aber muss ich gestehen, dass ich von der Politik, die Sie in ihrem Artikel vertreten, sehr wenig erbaut bin. Sie schreiben den unglaublichen Satz nieder, dass Polen sicher, vielleicht aber nicbt Russland für die Demokratie reif sei. Dieser Satz ist der schlimmste Verrath an der russischen Revolution, den man sich denken kann und zeugt gleichzeitig von der kurzsichtigsten Kirchthurmpolitik. Dic P.P.S. scheint also noch nicht zu wissen, dass die Geschicke aller im russischen Reiche lebenden Nationen in Petersburg und nicht in Warschau entschieden werden, dass der Sturz des Zarismus in Petersburg die Vorbedingung ist der Unabhängigkeit Polens, dass es heute gilt, alle Kräfte der Revolution gegen den Zaren zusammenzufassen. Sie glauben, die polnische Demokratie erringen zu können, ehe die russische crrungen wird. Sie trennen also die polnische Revolution von der russischen und aus dem Kampfe der polnischen und russischen Proletarier machen Sie einen Kampf der Polen gegen die Russen. Dabei kann ich nicht mithelfen..." Nach Kautskys Absage hat Lusnia seinen Artikel über „Dic Lage in Polen und Litauen” in den "Sozialistischen Monatsheften" (IX, I905, I, S. 234-4I) veröffentlichen können. Vgl. auch die vorangegangene Polemik zwischen Lusnia und Kautsky in: Die Neue Zeit XXII, I (r904) S. 559-67, 620-27, $652-57$.

4 Sowohl Axelrod (als Vertreter des erkrankten Plechanow) wie auch R. Luxemburg haben an der Sitzung des I.S.B. teilgenommen(Vorwärts, No I s, I 8. I. 1905. I. Beilage, S.3). 
3. Februar 1905 wandte sich der deutsche Parteivorsitzende in gleichlautenden Schreiben an die beiden Fraktionen, um - wie er ausführte „,in dem bedauerlichen Konflikt, der zwischen den Anhängern des Wperjod und der Iskra seit längerer Zeit ausgebrochen ist..., eine Intervention zu versuchen". Die Spaltung habe in der internationalen Sozialdemokratie "grosse Bestürzung und lebhafte Missbilligung erzeugt"; nunmehr aber bestehe angesichts der Entwicklung in Russland „allgemein die Erwartung, dass es gelingen werde, ... einen gemeinsamen Boden für den Kampf gegen den gemeinsamen Feind zu finden". ${ }^{1}$ Die streitenden Parteien sollten sich dem Spruch eines fünfköpfigen Schiedsgerichtes unterwerfen, das in Zürich unter dem Vorsitz Bebels tagen werde; für die Dauer der Verhandlungen habe jede Polemik zu ruhen.

Der menschewistische Parteirat stimmte dem Vorschlag Bebels am 7. Februar unter Berufung auf die „Einheits-Resolution” des Amsterdamer Kongresses ${ }^{2}$ zu und bat Kautsky und Klara Zetkin, als Sachwalter seiner Interessen in das Schiedsgericht einzutreten. Er unterliess es indessen nicht, gesondert darauf hinzuweisen, dass neben der „Mehrzahl der aktiven Genossen” auch die Zentral-Institutionen der Partei (Z.K., Zentralorgan) auf seiner Seite stünden, während Lenin es sei, der die Rechtmässigkeit dieser Führungsgremien nicht anerkenne. ${ }^{3}$ Lenin antwortete unter dem gleichen Datum mit einer eindeutigen Absage an den Vermittlungsvorschlag des deutschen Parteivorstandes: Die Spaltung der Partei sei jetzt eine „vollendete Tatsache" geworden, über die allein ein „Dritter Parteitag" zu befinden habe, nicht aber ausländische Genossen. ${ }^{4}$ Dieser Parteitag, den Lenins publizistisches Sprachrohr, der seit kurzem in Genf erscheinende "Vpered", 5 propagierte, war inzwischen von dem im Dezember 1904 geschaffenen provisorischen Organisations-Zentrum der Bolschewiki,

1 Das Schreiben Bebels an die Menschewiki wurde erstmals in Iskra No 86 (3./16.2.1905, S. 8) veröffentlicht; es war offenbar an Axelrod gerichtet, der es dem Parteirat zur Beantwortung vorlegtc. Der Brief an Lenin vom gleichen Tage: Sämtliche Werke VII (I929) S. 560 . Vgl. neuerdings die sowjet-marxistische Beurteilung der Rolle Bebels durch Botho Brachmann: August Bebels Stellung zur russischen Arbeiterbewegung in der Zeit der ersten russischen Revolution von 1905-1907, in: Deutsch-Slawische Wechselseitigkeit in sieben Jahrhunderten. Gesammelte Aufsätze, Berlin (Ost) I956, S. 647-72.

2 Vgl. S. 418, Anmerkung 2.

3 Parteirat der RSDRP(Sovet partii) an Bebel, 7. Febr. 1905: Iskra No 86, 3./16.2.1905, S.8.

4 Lenin an Bebel, 7. Febr. I905: Sämtliche Werke VII (1929) S. 14I. Bebel hat Axelrod am 5. März roos die Antwort Lenins im Wortlaut mitgeteilt. Der von Lenin erwähnte Brief an Greulich vom 5. Febr. I90s (Sämtl. Werke VII, I 29 ff.), den er Bebel in Abschrift übersenden wollte, war bis 5. März noch nicht in den Händen des deutschen Parteivorsitzenden (Bebel an Axelrod, 5.3.I 905, Axelrod-Archiv).

5 Das von Lenin gegründete Organ der Bolschewiki „Vpered” erschien erstmals am 4. Jan. 1905 in Genf. 
dem „Büro der Komitees der Mehrheit”, einberufen worden. ${ }^{1}$ Lenin hatte seiner Antwort an Bebel ursprünglich einen Schlussabsatz einfügen wollen, in dem er seiner Verärgerung über die Berliner Protektoren der Iskra-Fraktion Luft gemacht hatte. In einem ersten Entwurf seines Briefes war der Vorwurf enthalten, die deutsche Sozialdemokratie habe „ihr Möglichstes getan”, um den Weg zur Rettung der Parteieinheit zu versperren. Kautskys und Luxemburgs Stellungnahmen für die russische Minorität hätten eine ,ungemein grosse" Erbitterung hervorgerufen und die „famose Motivierung”, mit der Kautsky im Oktober 1904 den Abdruck der Lenin'schen Replik verweigert habe, sei „einfach ein Hohn” gewesen. ${ }^{2}$ Das russische „Büro der Komitees der Mehrheit", an das Lenin den Brief Bebels weitergeleitet hatte, reagierte - allerdings erst nach Wochen - zwar verbindlicher, aber im Kern doch negativ. In der Erklärung, die der „Vpered” am 23. März abdruckte, wurde Gewicht auf die Feststellung gelegt, dass die Parteispaltung "keinen persönlichen oder Gruppencharakter" trage, vielmehr Ausdruck eines „Zusammenstosses politischer Ideen” sei. Aus diesem Grund könne die Krise nicht durch ein ausländisches Schiedsgericht behandelt werden, sondern allein durch den bereits einberufenen Dritten Parteitag der Sozialdemokratie Russlands. ${ }^{3}$

Mit der Zurückweisung des deutschen Vermittlungsvorschlags durch Lenin schien in der Tat eine Situation einzutreten, wie sie von Kautsky im Dezember 1904 für diesen Fall vorausgesagt worden war: Lenin hatte sich vor der deutschen Sozialdemokratie ,ins Unrecht gesetzt". 4 Schon am 8. Februar ,wetterte” Kautsky im Gespräch mit dem Berliner „Vpered”-Vertreter Pjatnitzkij, dass die Bolschewiki durch ihre Weigerung ,viel verloren hätten und dass Lenin daran schuld sei, denn wenn sein Starrsinn nicht wäre, so könnte die russische Sozialdemokratie sich einigen". ${ }^{3}$ Er setzte Pjatnitzkij auseinander, dass „der Streit über die Organisation jetzt nicht [mehr] so wichtig" sei, zumal doch beide Fraktionen ,im allgemeinen gleichartige Prinzipien” vertreten. Kautsky wäre „sehr froh", so schrieb Pjatnitzkij am 9. Februar an Lenin, „uns ebenso vereinigt zu sehen, wie [sich] die Lassalleaner

1 Zur bolschewistischen Agitation für einen „Dritten Kongress” vgl. N. Sachov : Bor'ba za s'ezd Sobranie dokumentov, Ženeva 1904; Leninskij Sbomik V (1926); Tretij s'ezd RSDRP Sbornik dokumentov i materialov, Moskva I955.

2 Der Schlussabsatz des Briefentwurfes: Leninskij Sbornik V (1926), S. 172, sowie Lenin, Sämtliche Werke, VII (1929) Anm. 64.

3 Vpered No I I, 10./23.3.1905, S. 5. Vgl. dazu den von dieser Erklärung abweichenden Entwurf eines Briefes an Bebel vom 22 . Februar 1905 , den offenbar Lenin für das „Büro der Komitees der Mehrheit" abgefasst hat: Leninskij Sbornik V, S. $182 \mathrm{f}$.

4 Axelrod an Kautsky, I9. Dez. 1904 (Axelrod-Archiv).

5 O. Pjatnizki: Aufzeichnungen, a.a.O. S, 88 f, 
und die Eisenacher [1875 vereinigt haben]".1 Angesichts der offenkundigen und von Lenin nicht geleugneten Spaltungsbereitschaft der Bolschewiki wäre es freilich nicht verwunderlich gewesen, wenn die deutsche Parteispitze nunmehr vorbehaltlos Front gemacht hätte. Indessen hatte inzwischen auch die Iskra-Fraktion alles getan, um in Berlin klar werden zu lassen, dass ihre Methoden des Fraktionskampfes der Lenin'schen Machttaktik nicht nachstanden. Noch bevor sich das Schicksal des Schiedsgerichtes entschied, war das deutsche Verhältnis zu den Menschewiki in eine ernste Vertrauenskrise geraten, deren fortwirkende psychologische Folgen nicht immer durch die bestehenden persönlichen Beziehungen zwischen Kautsky und Axelrod aufgewogen werden konnten. Die Spannungen hatten sich an der für alle osteuropäischen Emigrantenorganisationen lebenswichtigen Finanzfrage entzündet, die, zumal nach den Petersburger Januarereignissen, hochexplosiven Sprengstoff in sich trug. In der Berliner RussenKolonie ${ }^{2}$ bestand seit August I 904 ein örtliches Koalitionsabkommen zwischen den Anhängern Lenins und der Iskra, dem sich in den Herbstmonaten auch Bundisten, Polen und Letten angeschlossen hatten. Dieses durch ein interfraktionelles Unterstützungskomitee ausgewiesene Modell für die fehlende Aktionseinheit der Parteispitzen hatte im Verkehr mit deutschen Stellen eine Vertrauensbasis geschaffen, die ausreichte, um mit der Verteilung der seit 1905 zusammenfliessenden Spendengelder beauftragt zu werden. Anfang Februar hatte jedoch der Berliner Vertreter der „Iskra”, Viktor Kopp (Sjurtuk), ${ }^{3}$ gegen diesen Modus Einspruch erhoben und unter Berufung auf Axelrod eine Zentralisierung des Verteilungswesens durch die Genfer Parteiinstitutionen der Menschewiki gefordert. ${ }^{4}$ Auf Grund dieser Haltung drohte Gefahr, dass nunmehr auch das „Vereinigte Berliner Komitee" die Spaltung der Gesamtpartei nachvollzog. ${ }^{5}$

Die Berliner Krise blieb dem deutschen Parteivorstand nicht verborgen. Kautsky intervenierte schon am 6. Februar bei Axelrod mit der Versicherung, dass das Verhalten des Iskra-Agenten „sehr böses Blut gemacht" habe. Wenn dieser Streit an die Öffentlichkeit komme, so warnte er seinen Züricher Freund, würde das, ,wie ich die Deut-

1 Proletarskaja Revoljucija No 2, 1933, S. 183.

2 Einzelangaben auf Grund mitteldeutschen Archivmaterials neuerdings bei Botho Brachmann: Russische Sozialdemokraten in Berlin 1905-1907, in: Zeitschrift für Geschichtswissenschaft VI (1958), S. 775-96.

3 Viktor Kopp-Sjurtuk ist mit dem späteren sowjetrussischen Rotkreuz-Vertreter in Berlin (19I9-2I) identisch.

4 Kautsky an Axelrod, 6. Febr. 1905 (Axelrod-Archiv).

5 Pjatnitzkij berichtet (Prolet. Revoljucija, No 2, I933, S. 183), Kopp sei am 7. Febr. r9o5 wegen Missachtung der Beschlüsse des Vereinigten Komitees ausgeschlossen worden. 
schen kenne, ihnen das ganze Sammeln verekeln und Ihr würdet wahrscheinlich alle zusammen nichts erhalten". ${ }^{1}$ Wenig später sah sich auch Bebel mit der Angelegenheit befasst und führte bei Kautsky Beschwerde über das Verhalten von „Axelrod und Genossen”, die sich ,allerdings etwas sehr den Löwenanteil [an den Spendengeldern] vorbehalten” hätten. Weder bekäme der Bund etwas, „noch werden sie den Leninisten etwas üb[er]geben". ${ }^{2}$ Bebel fand es „ein bisschen schroff", dass die Menschewiki überhaupt auf einen Anteil verzichten wollten, falls Lenin bei der Verteilung berücksichtigt werden sollte. Mit den Worten: „Ein Narr wer sich in ausländische Parteiangelegenheiten einmischt", zog er resignierend das Fazit seiner von beiden russischen Fraktionen gleichermassen enttäuschten Hoffnungen. In Übereinstimmung mit Bebel entschloss sich nun Kautsky zu einer Pferdekur an seinen russischen Freunden: Am I4. Februar schickte er einen fünfzehn Seiten umfassenden Brief nach Zürich, ${ }^{3}$ der Axelrod gleich eingangs mit der Feststellung überfiel, dass „gerade Ihr der Keil seid, der die Leute auseinandertreibt..." Besonders erbittert zeigte sich Kautsky über das „autokratische Verfahren”, mit der die Menschewiki über eine ihnen zur Verteilung anvertraute Summe von 10.000 Mark verfügten. Die Beschwerden der Polen, Letten und Bundisten hätten, so schrieb er, einen „guten Grund", weil „Ihr autokratisch den anderen gegenüber auftretet, sie fühlen lasst, dass Ihr sie geringschätzt und ihnen Euere Beschlüsse aufzwingen wollt, statt sie mit ihnen gemeinsam zu fassen". Diese unversöhnliche Art die es ihm unmöglich mache, "hier in Berlin weiter als einigendes Element zu fungieren", konstatierte Kautsky auch für das Verhalten der Menschewiki gegenüber den Anhängern Lenins. Zum ersten Male schien er sich auch in prinzipiellen Fragen von Axelrod zu distanzieren:

„... Es scheint mir, Ihr seid gerade so wie Lenin. Auch er ruft im Wperjod: wir wollen uns einigen, aber nicht mit Leuten wie Axelrod, Plechanoff etc. Ihr erklärt: Ja wir wollen uns mit Lenin einigen, aber erhält er einen Antheil von den Unterstützungen,

1 Kautsky an Axelrod, 6. Febr. I 905 (Axelrod-Archiv).

2 Bebel an Kautsky, 12. Febr. 1909 (Kautsky-Archiv D III, 92). Im gleichen Brief äussert sich Bebel zur Ablehnung seines Vorschlages durch Lenin: „...Die Russenschiedsgerichtssache zerschlägt sich. Lenin antwortet, er könne keine Zusage machen, darüber möge der Partcikongress entscheiden, der von ihm als dem Repräsentanten der Mehrheit der Partei einberufen worden sei. Da weiss man im voraus, was beschlossen wird..." Vgl. dazu Bebel an Axelrod, 20. Febr. I 905 (Abschrift im Axelrod-Archiv): „...A Aus dem Schiedsgericht wird also vorläufig nichts, und ich fürchte, es wird überhaupt nichts daraus, man wird schon eine Ausrede finden..."

${ }^{3}$ Kautsky an Axelrod, 14. Febr. Igos (Axelrod-Archiv). Der Brief trägt den Zusatz Bebels: „Bin mit vorstehendem einverstanden...” 
dann wollen wir damit nichts mehr zu tun haben.... Ihr versteht unter Einigung nicht die Einigung zweier gleichberechtigter Faktoren, sondern eine bedingungslose Unterwerfung der anderen.... Wie immer man über Lenin denken mag - ich habe keine hohe Meinung von ihm - seine Anhänger [aber] sind zum grossen Theil brave Parteigenossen, die wir aus dem revolutionären Kampfe nicht ausschalten können noch dürfen.... Ihr seid ausgezeichnete Marxisten, aber Euere Anschauungen über Organisation und den Verkehr mit Parteigenossen sind nicht die unsrigen.... Nun ich hoffe, dass die Massen in Russland gut machen, was ihre Führer im Ausland mangelhaft machen und dass sie nicht über dem Organisationspartikularismus die grosse Sache... auf ein niederes Niveau herabziehen." 1

Wie schwer Kautsky diese Distanzierung gefallen sein mag, zeigt die Tatsache, dass er am folgenden Tage - „um Missverständnisse zu vermeiden" - seiner Philippika einige versöhnlichere Zeilen nachschickte, ${ }^{2}$ die allerdings die Kritik an der versuchten Sprengung des Berliner Unterstützungs-Komitees und an der Schroffheit der Menschewiki gegenüber den kleinen nationalen Organisationen bestehen liessen. Kautsky erklärte, dass er „nach wie vor" Lenins Verfahren für ,ungerechtfertigt und schädlich" halte und ,prinzipiell und taktisch” mit Axelrod einverstanden sei. Er teile auch die Meinung, „dass der Schwerpunkt der Bewegung in Russland bei Euerer Organisation liegt und ihr die Führung zukommt". Allerdings dürfe dieser Führungsanspruch, ,nicht von vornherein als Bedingung des Zusammenarbeitens" erhoben werden; die „Uberlegenheit” der Iskra-Richtung müsse vielmehr ,von selbst... als eine Thatsache, nicht als ein Anspruch hervorgehen". ${ }^{3}$

Diese einlenkenden Bemerkungen machen darauf aufmerksam, dass die Auswirkungen der kritischen Einsichten Kautskys auf seine prinzipielle Haltung zu den Menschewiki nicht überschätzt werden

1 Ibid. - Bebel beschwerte sich ebenfalls in einem Brief an Axelrod vom 20. Febr. 1905 (Abschrift im Axelrod-Archiv) über die Handhabung der Geldangelegenheiten durch die Menschewiki. Zu einer Einigung über die Verteilung der deutschen Spendengelder ist es erst im September I 905 auf der Basis 50 : so gekommen, nachdem eine Vereinbarung zwischen der menschewistischen Organisationskommission und dem bolschewistischen ZK am I 2. Aug. I 905 die Voraussetzungen geschaffen hatte. Vgl. Pis'ma P. B. Aksel'roda, a.a.O. S. I 6 f., sowie Gurwitsch an Kautsky, 2. Sept. I905 (Kautsky-Archiv D XI, 3 I 3 ). Das I.S.B. hat im Sommer I909 eine Summe von $18.934,30$ frs auf folgende Weise verteilt: Sozialrevolutionäte 5.049,23, Menschewiki, Bolschewiki und jüdischer Bund je 2.524,5 I, P.P.S. und SDKPiL je 3.155,77 frs. (Rapport du Secrétariat du Burcau Soc. Int. pour les mois de Juin, Juillet et Août I 905, Bruxelles, 22 Septembre I905. KautskyArchiv G 3).

2 Kautsky an Axelrod, r5. Febr. 1905 (Axelrod-Archiv).

3 Ibid. 
dürfen. Während aus dem folgenden Briefwechsel Bebels mit Axelrod eine spürbare Abkühlung der Beziehungen erkennbar wird, hat Kautsky seine Hände auch in den kommenden Wochen von dem Kreis um Axelrod, Dan und Martow nicht zurückgezogen. ${ }^{1}$ Andererseits kann nicht übersehen werden, dass auch der Redakteur der „Neuen Zeit" nachwirkende Erfahrungen aus den russischen Exilkonflikten gezogen hatte, die ihn veranlassten, seine persönlichen Bindungen immer wieder zu prüfen. Bei aller Übereinstimmung mit den theoretischen und taktischen Leitbildern der Iskra-Anhänger hat sich dabei freilich sein Eindruck weiter verhärtet, dass die doktrinären und rücksichtslosen Züge der russischen Fraktionskämpfe es schwer machten, die Methoden seiner menschewistischen Freunde von denen Lenins abzugrenzen.

Die psychologische Aufnahmebereitschaft der europäischen Parteiöffentlichkeit gegenüber dem Wirken des Popen Gapon und den Terrorakten der Sozialrevolutionäre ist von Kautsky nicht allein als Problem der russischen Sozialdemokraten empfunden worden. Er sah sich hier zugleich vor eine Grundfrage der sozialdemokratischen Taktik gestellt, die in den Konflikt des Parteivorstandes mit seinem Zentralorgan, dem „Vorwärts”, hineinreichte. Die Beurteilung der russischen Terroristen oder der ,zufälligen Führer" 2 des Petersburger Proletariats war somit zu einem Spannungsfeld auch für die deutsche Partei geworden. Selbst Bebel hat in diesen Wochen keine Bedenken getragen, die Forderungen der Sozialrevolutionäre nach Geldzuweisung gegenüber den Menschewiki zu vertreten. In einem Briefe an Axelrod vom 5. März begründete er diese Bereitschaft mit der befriedigenden Feststellung, er ersehe "aus den letzten Kundgebungen der Iskra, dass Sie [Axelrod] in der Taktik sich bis zu einem gewissen Grade diesen [den SR] angenähert haben". ${ }^{3}$ Der prinzipienfeste Kautsky war indessen nicht schwankend geworden, sondern hat die russischen Sozialdemokraten vor der öffentlichen Meinung wieder und wieder in Schutz genommen. Immerhin gestand er Axelrod am 2. März ein: „Wenn man die Leute [die SR] hört, könnte man wirklich

1 Vgl. Kautsky an Axelrod, 2. März I gos (Axelrod-Archiv): „...Übrigens stehe ich aber sacblich Euch sehr nahe, denn ich halte das Vorgehen Lenins ebenso wie Ihr für verbrecherisch, namentlich seine versteckte Ablehnung des Schiedsgerichts und billige auch Euere Abschätzung der Geldbedürfnisse der verschiedenen Fraktionen. Nur formell differiere ich von Euch, indem ich der Ansicht bin, dass es besser gewesen wäre, wenn dasselbe Resultat nicht einseitig von Euch beschlossen, sondern das Produkt des gemeinsamen Beschlusses aller sozialdemokratischen Fraktionen wäre..."

2 So R. Luxemburg über Gapon: Die Revolution in Russland, in: Die Gleichheit (Stuttgart) 8.2.1905 (Ausgewählte Reden und Schriften, Bd. 2, S. 216).

3 Bebel an Axelrod, 5. März 1905 (Abschrift im Axelrod-Archiv). 
glauben, sie seien gute Marxisten". Auch meinte er, dass sie jedenfalls ,in der deutschen Sozialdemokratie Platz finden" würden, da sie ,im Grunde nicht weniger Sozialisten als Bernstein und David" seien. ${ }^{1}$ Allerdings, so fügte er beruhigend hinzu, er persönlich halte weder die Sozialrevolutionäre noch seine beiden Opponenten aus dem Lager des deutschen Revisionismus für wirkliche Sozialdemokraten. Ende März wandte sich Kautsky in der „Leipziger Volkszeitung” 2 gegen den Aufruf Gapons zur Einigung der russischen Sozialisten, dem sich auch das Internationale Sekretariat des I.S.B. angeschlossen hatte. Im „Vorwärts” war dieser Appell zusammen mit Auszügen aus dem sozialrevolutionären Parteiorgan „Revoljucionnaja Rossija” abgedruckt worden, ${ }^{3}$ das auf die Einigungsbemühungen dieser Partei aufmerksam gemacht hatte. Kautsky bestritt in seiner Replik energisch, dass Gapon, der erst vor wenigen Wochen mit dem Sozialismus in Berührung gekommen sei, imstande wäre, einen Beitrag zur Beilegung der Fraktionskämpfe in Russland zu leisten. ${ }^{4}$ Als der "Vorwärts” am 30. März gar Karl Marx als Zeugen für die These anrief, dass der Terror eine ,spezifisch russische Taktik" und ,geschichtlich unvermeidlich" sei, ${ }^{5}$ beschwerten sich Kautskys russische Freunde, „dass gerade die russischen Genossen auf eine so hartnäckige Missverständnis [sic] bei den deutschen Genossen stossen". ${ }^{6}$ Der Kommen-

1 Kautsky an Axelrod, 2. März I90s (Axelrod-Archiv). Kautsky berichtet u.a. von einem nach Berlin gekommenen Sozialrevolutionär, der von Liebknecht und Kurt Eisner protegiert werde. (Es könnte sich dabei auch um Theodor, den Bruder Karl L.'s handeln, den Ljadow solcher Sympathien bezichtigt hat; s.Iz žizni partii, a.a.O. S. I 7). - Zur Haltung des rechten Flügels der deutschen Sozialdemokratie zum russischen Parteistreit vgl. die Bemerkungen von Hugo Poetz (Sozialistische Monatshefte, IX, 1905, II, S. 815): „... Bei diesem selbstmörderischen Treiben finden aber beide Fraktionen [d.h. Bolschewiki und Menschewiki] auch noch Zeit, nach wie vor den Sozialisten-Revolutionären bei ihrer praktischen Tätigkeit in den Rücken zu fallen..."

2 Karl Kautsky: Gapon und die Einigung der russischen Sozialisten, in: Leipziger Volkszeitung No 73, 29.3.1905, Sächsische Arbeiter-Zeitung (Dresden) No 74, 30.3.1905; russisch: Iskra No $9\left[\begin{array}{l}25 \cdot 3 . / 7 \cdot 4 \cdot 1905 . \\ .\end{array}\right.$

${ }^{3}$ Aufruf Gapons zur Einigung der tussischen Sozialisten. Vorwärts No 73, 26.3.1905. - Auf Grund dieses Aufrufes kam im April r 905 unter massgeblicher Beteiligung der Sozialrevolutionäre eine Konferenz in Genf zustande. Während die Menschewiki die Teilnahme von vornherein verweigert hatten, waren von den Bolschewiki, dem jüdischen Bund, sowie von den lettischen und armenischen Sozialdemokraten Vertreter entsandt worden, die jedoch am ersten Sitzungstage die Konferenz (aus Protest gegen die Zulassung einer lettischen Splittergruppe) wieder verliessen. Vgl. Iskta No 88, 23.4./6.5.1905 und Lenins Ausführungen vor dem III. Parteitag (Tretij očered. s'ezd RSDRP. Polnyi tekst protokolov, Ženeva r9o5, S. 338-43). Die Resolutionen der Genfer Konferenz in: Revoljucionnaja Rossija No 65, 25.4.1905; Vorwärts No 100, 29.4.1905; Arbeiter-Zeitung (Wien) No I 23, 5.5.1905.

4 Leipziger Volkszeitung Nr. 73, 29.3.1905.

5 Karl Marx über Terrorismus, in: Vorwärts No 76, 30.3.1905.

6 Gurwitsch an Kautsky, 3 1. März 1905 (Kautsky-Archiv D XI, 307). 
tator des „Vorwärts” hatte der Marx'schen Würdigung der „Narodnaja Volja" überdies einige mehrdeutige Bemerkungen angefügt, die sich ,gegen gewisse anarchistelnde Gruppen russischer Revolutionäre" richteten, ,die in Genf ihr Unwesen treiben,... deren Einfluss auf das Schlachtfeld in Russland [aber] gleich null sei". ${ }^{1}$ Als auch Axelrod darüber Klage führte, „dass die Correspondenten der internationalen Parteipresse gefliessentlich verschweigen die vielen, ja prägnanten Thatsachen... welche den Einfluss der Socialdemokratie auf das kämpfende Proletariat illustrieren", ${ }^{2}$ - entschloss sich Kautsky, im Sinne der „Iskra” in der „Neuen Zeit” zu den Differenzen zwischen Sozialdemokraten und Sozialrevolutionären Stellung zu nehmen. ${ }^{3}$

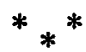

Das Verhältnis Kautskys zu seinen russischen Freunden stand wenig später jedoch erneut vor schweren Belastungsproben. Axelrod hatte im April für die Jubiläumsnummer der "Iskra" (No Ioo) einen Beitrag erbeten, den Kautsky dazu benutzte, seine Gedanken zur Spaltung der Sozialdemokratie Russlands der veränderten Lage in der Partei anzupassen. ${ }^{4}$ Veranlassung dazu gaben ihm die Resolutionen des Kongresses jener russischen Parteikomitees, die Ende April dem gemeinsamen Ruf des Zentralkomitees und des bolschewistischen Büros nach London gefolgt waren. Auf diesem von Lenin bestimmten „Dritten Kongress der RSDRP”, dem die Menschewiki in Genf eine fast gleichstark besuchte Separatkonferenz entgegengesetzt hatten, war die organisatorische Spaltung der Partei beschlossen worden. ${ }^{5}$ Auch die Iskra-Anhänger beschritten durch Schaffung einer "Organisations-Kommission" mit den ihnen gewogenen Komitees den Weg zur formellen Absonderung. ${ }^{6}$ Kautsky gab in seinem Artikel

1 Vorwärts No 76, 30.3.1905.

2 Axelrod an Kautsky, 2. April I 905 (Kautsky-Archiv D II, 3 I 7 ).

${ }^{3}$ Die Differenzen unter den russischen Sozialisten, in: Die Neue Zeit XXIII, 2 (1905)

S. 68-79, russisch: Iskra No 97, I8.4./x.5.I905, S. 2-6. Dazu die Replik des Vorwärts No 93, 19.4.1905, S. I.

4 Der Brief Axelrods mit der Aufforderung an Kautsky ist offenbar nicht erhalten. Sein Inhalt kann aus der Antwort Kautskys an Axelrod vom 8. Mai i gos rekonstruiert werden (Axelrod-Archiv).

5 Der „Dritte Kongress der RSDRP” tagte vom 25. April bis Io. Mai r 905 in London. $\mathrm{Zu}$ den Diskussionen vgl. Tretij očerednoj s'ezd R.S.D.R.P. Polnyi tekst protokolov. Izd. C.K., Žcneva I905. Die Bolschewiki hatten eine deutsche Übersetzung der Resolutionsentwürfe verbreitet; Kautsky sprach sich gegen die Veröffentlichung dieser Dokumente in der deutschen Parteipresse mit der Begründung aus, sie würden "der Mehrzahl der Leser ein ganz falsches Bild der Verhältnisse” geben, auch hätten sie „zu keinem ungelegeneren Zeitpunkt" erscheinen können.(Leipziger Volkszeitung No I35, I 5.6.1905.) Vgl. S. 438, Anm. 2.

6 Die menschewistische Konferenz tagte in Genf parallel zu den Sitzungen des Londoner bolschewistischen Kongresses. Vgl. Pervaja obščerusskaja konferencija partijnych rabotnikov. Otdel'noe priloženie k No Ioo Iskry, Ženeva I 905. 
der Hoffnung Ausdruck, dass ,gerade diese Spaltung... die Grundlage zur Einigung" werden könne, weil sie - wie er Axelrod am 8. Mai erläuternd schrieb - „den Rattenschwanz von Kompetenzkonflikten” zerschlage. Diejenige Fraktion aber, die den „ohne eine Spur einer sachlichen Differenz" ausgefochtenen Zwist jetzt, da die organisatorische Trennung vollzogen sei, als erste durch versöhnliche Schritte beenden helfe, werde „den grössten Nutzen davon haben". ${ }^{1}$ In dem für die „Iskra” bestimmten Beitrag warnte Kautsky beide Seiten: Die internationale Sozialdemokratie werde es als ein "tatsächliches Verbrechen am Befreiungskampf des Proletariats" werten, wenn eine der Fraktionen "durch ihre Empfindlichkeit oder Rücksichtslosigkeit" das Einigungswerk erschwere oder störe. ${ }^{2}$

Obwohl Kautsky seinem Freunde Axelrod anheimgestellt hatte, den Artikel ,in den Papierkorb” zu werfen, falls er "Verlegenheit bereitet", 3 antwortete ihm dieser am 10. Mai mit einem Katalog grollender Belehrungen: Die Erwartungen Kautskys auf eine beschleunigte Beendigung der Parteikrise beruhten „auf irrtümlichen Voraussetzungen, ....auf vermeintlichen Thatsachen", so parierte Axelrod, ,die nur von falschen Mündern herumkolportiert und Dir eingeflüstert worden sind. Vor allem der sogen. Kompetenzkonflikt..." Die „durchaus irrigen” Andeutungen des Artikels brächten ihn in die „peinliche Lage”, Kautsky berichtigen zu müssen, wenn der Beitrag in dieser Form in der "Iskra" erscheine.4 Axelrod disqualifizierte Lenins Parteitag mit den alten und Kautsky wohlbekannten Prädikaten als „bonapartistische Verschwörung”, „unerhörte Überrumpelung der Partei”, „Clique in der Art des früheren französischen Generalstabs in der Dreyfusaffäre" usw. Indessen scheint Axelrod mit seiner verbitterten Feststellung, dass Kautsky offenbar seine Schilde-

1 Kautsky an Axelrod, 8. Mai 1905 (Axelrod-Archiv).

2 Wohl auf Grund der Einwände Axelrods erschien der Artikel Kautskys zunächst in der Leipziger Volkszeitung (Die Spaltung der russischen Sozialdemokratic. No 135 , 15.6.1905) und erst 14 Tage später in No ro2 der Iskra (15./28.6.1905, S. 7). Lenin hat diesen Artikel mit einem „offenen Brief” an die Redaktion der Leipziger Volkszeitung beantwortet, in dem er energisch gegen den Versuch protestierte, „unsere Stimme in der deutschen s.d. Presse mundtodt zu machen mittelst so eines groben, mechanischen, unerhörten Mittels wie Boycott..." (Leninskij Sbornik XVI, S. I Io). Der Brief ist in der Leipziger Volkszeitung nicht veröffentlicht worden.

3 Kautsky an Axelrod, 8. Mai 1905 (Axelrod-Archiv).

4 Axelrod an Kautsky, Io. Mai 1905 (Kautsky-Archiv D II, 3 I 8). Axelrod hat diesen Brief am I4. Mai durch Ausführungen über die mehrfachen Friedensversuche der Menschewiki ergänzt; er führte den Misserfolg dieser Bemühungen darauf zurück, dass „ein Theil der Leninisten... völlig korrumpiert" sei (Axelrod an Kautsky, 14.5. I905, Kautsky-Archiv D II, 319). - Den Beitrag Kautskys hat die Redaktion der Iskra tatsächlich mit cinschränkenden Bemerkungen versehen, die den Optimismus Kautskys hinsichtlich einer jetzt möglich gewordenen Einigung als das Ergebnis falscher Informationen zurückwiesen (Iskra No 102, 15./28.6.1905, S. 7). 
rungen ,durchaus parteiisch” finde, recht genau den Kern der Verzweiflung seines Berliner Freundes getroffen zu haben. Denn Kautsky reagierte aussergewöhnlich scharf: Er sehe in seinen Darlegungen „nirgends einen Irrthum”, schrieb er am 1 3. Mai nach Zürich, zumal Axelrods Brief ihm „keine einzige 'Thatsache” mitgeteilt habe, die für ihn neu wäre oder seine Auffassung als falsch erweise:

„Du scheinst es schmerzlich zu empfinden, dass ich Lenin nicht als Verschwörer und Fälscher brandmarke, aber wenn ich das thäte, wie könnte ich dann auf Einigung hinwirken?... Durch Wiederholung der Beschuldigungen des Bonapartismus, Schweitzerianismus, Antidreyfusianismus etc. wird die Einigung nicht gefördert, sondern unmöglich gemacht. Es ist dringend nötig, dass Ihr zur Einigung kommt. Euere Spaltung wird immer mehr ein unerhörter Skandal und ich bemerke leider, dass beide Seiten gleich hartnäckig-verbissen in der Bekämpfung der Gegenseite sind. Ihr steht beide in der Gefahr, den russischen Marxismus vor der gesamten Welt zu kompromittieren.

Es ist heute schon unmöglich, Euch zu vertheidigen, und wie mir geht es sicher auch den anderen nichtrussischen Marxisten. Alle Welt lacht über Euch, wenn man mich fragt: warum streiten sich mitten in der Revolution die russischen Marxisten? Und ich nichts antworten kann als: weil Axelrod und Plechanoff Lenin für einen Intriganten halten und dieser es, nach allem, was ich von ihm weiss, wahrscheinlich auch ist. Alle Welt lacht über Marxisten, die aus diesem Grunde und einzig aus diesem, ihre ganze Partei in einem Moment lahmlegen, der vielleicht für ein Jahrhundert entscheidend ist. Also unterdrückt Eure persönliche Wuth, sonst kommt Ihr in Gefahr, vom Marxismus des Auslandes aufs schärfste desavouiert zu werden. Bisher haben wir Euch verteidigt. Aber jetzt fehlt uns jeder vernünftige Grund dazu. Und persönliche Sympathien genügen dazu nicht..." 1

Diese eindeutige Charakterisierung der russischen Fraktionskämpfe, die die unversöhnliche Hartnäckigkeit beider Seiten gleichermassen beklagte, hat sich in diesen Wochen über Kautsky hinaus zu einer förmlichen Empörung der führenden deutschen Genossen gegen die russischen Exilsozialisten gesteigert. Bebel war Ende Mai gar mit dem Gedanken umgegangen, den russischen „Führern” in einer „öffentlichen Erklärung” der deutschen und der österreichischen Partei darzutun, ,wie man im Ausland über ihr Treiben denkt". ${ }^{2}$ Am 29. Mai attackierte er Axelrod unter Verweis auf die nach Russland

1 Kautsky an Axelrod, r3. Mai 1905 (Axclrod-Archiv).

2 Bebel an Adler, 30. Mai igos (V. Adler, Briefwechsel, S. 455). 
übergreifenden Auswirkungen dieses „kleinlichen Parteigezänks”: „Es muss offen ausgesprochen werden, der Einfluss der Emigration auf die russische Bewegung, so wirkungsvoll er ehedem war, ist im Augenblick ein direkt unheilvoller und schädlicher. Ich bin überzeugt, wenn erst die Kenntnis dieser Vorgänge in weiteren Kreisen bekannt wird, ein Sturm der Entrüstung ausbricht und die Neigung zu Unterstützungen ganz und gar verschwindet. Ich bedauere ganz ausserordentlich, dies schreiben $\mathrm{zu}$ müssen, aber es wäre gewissenlos, wollten wir darüber schweigen. Es ist doch auch ein bisher nie dagewesener Fall, dass mitten in der Revolution die Führer im Ausland es fertigbringen, 30 Tage lang einen Kongress abzuhalten, der schliesslich mit der Verschärfung der Gegensätze endigt. Eine solche Handlungsweise grenzt an Gewissenlosigkeit und komplette Unfähigkeit, Führer der Bewegung zu sein.

Ich habe nichts dagegen einzuwenden, wenn Sie dieses mein Urteil, das sich mit dem der wissenden Genossen in Deutschland deckt, den weitesten Kreisen der russischen Genossen mitteilen."1

Von der Verstimmung und Erbitterung der deutschen Parteiführung, die sich jetzt gegen beide Fraktionen der Sozialdemokratie Russlands richtete, blieb in den folgenden Wochen vor allem jene Erkenntnis haften, die Bebel in seiner scharfen Erklärung entwickelt hatte: Die Emigration, die einer spontanen Massenbewegung den Weg weisen sollte, versagte in entscheidender Stunde. Selbst das Bemühen Kautskys, die Schärfen der russischen Fraktionskämpfe aus den Sonderbedingungen eines einseitig von der Theorie her bestimmten „Emigrantenmarxismus" abzuleiten, hat ihm die Hoffnung nicht wiedergegeben, dass seine Genfer Freunde, in der jetzigen Situation noch etwas für die revolutionäre Praxis tun können": ${ }^{2}$ "So sehr ich... die Axelrod und Plechanoff persönlich hochschätze", schrieb er an Adler, „so wünsche ich doch, dass in Russland Leute erstehen, die sie aus der Parteileitung drängen und ersetzen (und das gilt auch für Lenin)". ${ }^{3}$ Während Kautsky aber die persönlichen Beziehungen zu Axelrod und Gurwitsch-Dan nicht abreissen liess, hat sich Bebel mehr und mehr von den russischen Parteiangelegenheiten zurückgezogen. Am 25. Juni 1905 hat er sich mit einem Schreiben an das Internationale

1 Bebel an Axelrod, 29. Mai 1905 (Abschrift im Axelrod-Archiv).

2 Kautsky an Adler, 2o. Juli I 905 (V. Adler, Briefwechsel, S. 464 f.). Kautsky, der in diesem Bricf bei Adler für eine Verlegung der Iskra-Redaktion von Genf nach Wien eintritt, war am I4. Juli von Gurwitsch von den Plänen der Redaktion unterrichtet worden, "möglichst bald (nach I-2 Wochen) nach Wien zu übersicdeln..." (Kautsky-Archiv D XI, 3 II). Der erste, im Kautsky-Nachlass erhaltene Brief Gurwitschs aus Wicn stammt vom 2. Scpt. Igos (D XI, 3I3).

3 Ibid. 
Sozialistische Büro gewandt und angeregt, dass „das Exekutivkomitee des [I.S.B.] die Sache in die Hand nimmt". ${ }^{1}$ Die seitdem unternommenen Versuche, die Einigungsbemühungen unter Einschaltung des I.S.B. voranzutreiben, sind von Bebel mit der kategorischen Feststellung begleitet worden, er persönlich ,rühre in der ganzen Sache keinen Finger mehr, es sei denn, die streitenden Parteien stellten gemeinsamen Antrag".2 Es komme ihm "geradezu lächerlich" vor, erklärte er Axelrod Anfang Juli, „dass wir uns förmlich zu einer Verständigungskonferenz aufdrängen sollen, von der die Beteiligten selbst nichts wissen wollen". 3 Auch die "Leipziger Volkszeitung” hat sich den harten Tönen angeschlossen und Anfang August der auf Privatbriefe beschränkten Kritik zur Publizität verholfen. Angesichts der bevorstehenden Wahlkampagne für die Bulygin'sche Duma sei es ein „Verbrechen”, so hiess es in einem Leitartikel, die Spaltung weiter aufrechtzuerhalten:

„Meinungsverschiedenheiten... müssen verschwinden, wo es sich darum handelt, den Stoss in das Herz des Feindes zu führen... Die streitenden Führer der beiden russischen sozialdemokratischen Fraktionen müssen sich darüber klar sein, dass der Wirrwarr, den sie angestiftet haben, auch die Aktionsfähigkeit der sozialdemokratischen Organisationen der Polen, der Litauer, der Letten usw. beeinträchtigt. Die Verantwortung dafür, die Kräfte der Revolution durch ihren kleinlichen Hader zu hemmen, können sie nie und nimmer tragen..." 4

1 Text des Briefes: Lenin, Sämtliche Werke VIII (1931) S. 581. Zu den Massnahmen des I.S.B., die durch die von Lenin (nach dem Kongress) geforderte Neurcgelung der Vertretung der RSDRP zusätzlich angeregt wurden, vgl. Rapport du Secrétariat du Bureau Soc. Int. pour les mois de Juin, Juillet et Août I905, Bruxelles, 22 Septembre r9os (hektographiert im Kautsky-Archiv G 3), sowie Lenin: Sämtl. Werke VIII, S. 9-1 3, 435 f.

2 Der Brief Bebels an Axelrod, der im Axelrod-Archiv nicht enthalten ist, wird im Brief Gurwitschs an Kautsky vom 14. Juli rgos (Kautsky-Archiv D XI, 3 II) im Wortlaut wiedergegeben.

3 Ibid.

4 Zarischer Trug und rcvolutionärer Kampf (Leitartikcl), in: Leipziger Volkszeitung No I80, 7.8.1905, S. I f. Dieser Artikel billigte im übrigen die Taktik der Menschewiki gegenüber den Wahlen zur sogenannten „Bulygin'schen Duma” und sprach sich gegen den von Lenin propagierten "Absentismus" aus. Rosa Luxemburg dagegen hat wenig später in einem Brief an Axelrod (undatiert, Axelrod-Archiv) Einwände gegen diese Haltung der Iskra erhoben; sic wolle sich dazu aber - wie sie Axelrod versicherte - nur "in der loyalsten Form" öffentlich äussern. Dieser Brief R. Luxemburgs, der durch den Artikel Martows in der Frankfurter "Volksstimme" (Beilage zu No 199, 26.8.1905) angeregt wurde, ist eines der frühesten Zeugnisse für den von ihr seither vertretenen Boykott-Gedanken. Vgl. Rosa Luxemburgs spätere polemische Bemerkungen gegen Plechanow und die "Iskra" in ihren Briefen aus Warschau (Januar bis April 1906): Briefe an Karl und Luise Kautsky, Berlin 1923, S. 94 ff.; zu den Differenzen zwischen R. Luxemburg und der Iskra ferner: Lenin, Sämtl. Werke VIII (I93I) Anm. I3I. 
Die Reaktion im russischen Exil auf diesen Ansturm der Kritik hat indessen nur schmale Pfade geöffnet, die einer Einigung hätten entgegenführen können. Den Weg einer Aussprache vor dem Forum des I.S.B., den Kautsky während des Sommers anregte, sind die Menschewiki nur mit halbem Herzen mitgegangen. Sie wurden wie eh und je von der Überzeugung zurückgehalten, der Gegner wolle nicht die Vereinigung, sondern eine "Annektion in der Art der Elsass-Lothringen [sic]". "Bei Kautsky allein hofften sie auf Verständnis dafür, „dass nicht nur der böse Wille, der durch allgemeine moralische Predigten und Vorwürfe corrigiert werden kann, der Grund der Trennung” sei. „Es ist gewiss leicht”, klagte Gurwitsch-Dan am 25. Juni, „die Einigung um jeden Preis zu fordern,... [aber] es gibt Preise, die die Sache selbst vernichten, derentwillen sie gezahlt werden". 2 Vor allem die Zurückhaltung Bebels hat die Iskra-Anhänger sehr geschmerzt: „Ich muss offen sagen”, schrieb Dan drei Wochen später nach Berlin, ,dass mich das ganze Benehmen Bebels wundert. Er hat zuerst den Vorschlag des Schiedsgerichtes gemacht und hat an Axelrod sich geäussert: wenn Lenin darauf nicht eingeht, so ist er für uns ein toter Mann. Wir gingen darauf ein, Lenin nicht”. Bebel aber habe seine Zusage nicht eingelöst, er spreche jetzt vielmehr davon, „die Beteiligten" beider Richtungen wollten die Einheit nicht. ${ }^{3}$

Lenin selbst hat den im Sommer 1904 im Wettbewerb um die Gunst der Deutschen erlittenen Prestigeverlust nicht verwinden können, zumal er in der Zwischenzeit seinen Eindruck der "Parteilichkeit" immer wieder bestätigt sah. Es sei nicht schwer zu verstehen, formulierte er am 24. Juli eine Eingabe an das I.S.B., „warum viele Genossen in Russland geneigt sind, die deutsche Sozialdemokratie... als parteiisch und äusserst voreingenommen zu betrachten". Schon vier Wochen vorher hatte Lenin in einem offenen Brief an die Redaktion der „Leipziger Volkszeitung" Kautsky das Recht abgesprochen, als Schiedsinstanz aufzutreten: „Er [Kautsky] war immer parteilich im jetzigen Kampf innerhalb der russischen Sozialdemokratie”, hiess es $\mathrm{da}$, „aber wer parteilich ist, thut es besser nicht zu viel über Unparteilichkeit $z u$ sprechen um nicht weder [wegen] Heuchlerei gewiesen [verwiesen] zu werden". "Glauben Sie keinem Worte davon", rief Lenin den deutschen Genossen zu, „was Ihnen sogenannte unparteiliche Deutsche über unsere Spaltung erzählen..."5 Auch Lenins

1 Gurwitsch an Kautsky, 25. Juni 1905 (Kautsky-Archiv D XI, 308).

2 Ibid.

${ }^{3}$ Gurwitsch an Kautsky, 14. Juli rgos (Kautsky-Archiv D XI, 31 1 ).

4 Sämtliche Werke VIII (1931) S. 13.

${ }^{5}$ Leninskij Sbornik XVI, S. x Io (vgl. S. 438, Anm. 2). 
Anhänger, die seine Kompromisslosigkeit durchaus nicht immer im gleichen Masse teilten, haben sich von den deutschen Genossen schlecht behandelt gefühlt. So charakterisierte Lydin vor dem „Dritten Parteitag" den von Lenin zurückgewiesenen Schiedsgerichtsvorschlag als "Illustration einer verächtlichen Haltung”, die darin zum Ausdruck komme, dass Bebel die russischen Genossen "wie Kinder" behandele. ${ }^{1}$ Auch andere Diskussionsredner vertraten die Ansicht, „der ruhmreiche Führer der deutschen Sozialdemokratie" habe die Russen „wie Halbwüchsige zurechtweisen und belehren" wollen, wobei er offensichtlich ,von unseren verehrten Genossen aus der Redaktion der Iskra in die Irre geführt worden" sei. ${ }^{2}$ So ist aus dem Kreise der Bolschewiki nach dem fehlgeschlagenen Versuch Lydins, der jetzt über ein Jahr schon zurücklag, die Vermittlung von aussen nicht wieder gesucht, sondern eher gemieden worden.

Als nach dem „Oktober-Manifest” des Zaren das Gros des russischen „Emigrantenmarxismus” nach Petersburg übersiedelte, sind der deutschen Sozialdemokratie die Möglichkeiten der Einwirkung auf sehr natürliche Weise entglitten. „Man lebt wie im Taumel, die revolutionäre Luft wirkt wie Wein...", schrieb Dan am 9. November in seinem ersten Petersburger Brief an Kautsky nach Berlin, ${ }^{3}$ - und in der Tat: jetzt war es die Revolution selbst, die in den aus der Genfer Atmosphäre herausgeführten Streit einzugreifen begann. Das Erlebnis, erstmals vor Massenversammlungen sprechen zu können, der Eindruck der ,grossen Macht, die sich der hier eingerichtete 'Rath der Arbeiterdelegierte[n]' erworben hat", ${ }^{4}$ die mit Bangen verfolgte Streikbewegung in Petersburg, die blutige Niederwerfung des Moskauer Dezember-Aufstandes, - all das wirkte zusammen, um die russischen Sozialdemokraten über regionale Aktionsabkommen hinaus auch die formelle Wiedervereinigung der Partei suchen zu lassen. ${ }^{5}$ Vor allem aber war es wohl das gemeinsam getragene Bewusstsein von der bedrohten Revolution, das die feindlichen Brüder im April I 906 nach Stockholm geführt hat, ${ }^{6} \mathrm{zu}$ spät freilich für einen neuen Versuch, das stabilisierte System des autokratischen „Scheinkonstitutionalismus" noch einmal in den Grundfesten zu erschüttern.

1 Tretij očerednoj s'ezd R.S.D.R.P. Polnyj tekst protokolov, Ženeva I905, S. 38.

2 Ibid. S. 46.

${ }^{3}$ Gurwitsch an Kautsky, 27. Okt./9. Nov, 1905 (Kautsky-Archiv D XI, 314). Lenin traf am 7. Nov. x9os in Petcrsburg ein.

4 Ibid.

5 Vgl. J. Martow: Dic Geschichte der russischen Sozialdcmokratic, Berlin 1926, ذ. I 53 f., $172 \mathrm{ff}$.

6 Zum „Vercinigungsparteitag” vgl. Protokoly Ob'edinitcl'nago S'ezda Rossijskoj Social 'demokratičeskoj Rabočej Partii, sostojavšagosja v Stokgol'me v 1906 g., Moskva 1907. 420 S. - Der Kongress tagte vom 23. April bis 18. Mai rgo6. 
Inzwischen aber war die russischen Revolution in unmittelbarer Weise auch auf die deutsche Sozialdemokratie zurückgeschlagen. In den seit dem Jenaer Parteitag belebten Diskussionen um den Massenstreik ist von der sich formierenden deutschen „Linken” immer wieder mit den „Lehren der russischen Revolution” gefochten worden. Den Ruf zu ausserparlamentarischer Massenaktivität, den Rosa Luxemburg aus Warschau und Petersburg nach Deutschland zurückbrachte und in die Taktik einer Massenpartei umzupflanzen versuchte, hat in der Folgezeit Fronten aufbrechen lassen, die den Weg der deutschen Vorkriegssozialdemokratie bis zum Ende begleitet haben. ${ }^{1}$ Indessen ist die parteioffizielle Haltung gegenüber den Problemen und Kämpfen der russischen Sozialdemokraten nach den Einsichten der Jahre I904 und r905 kaum wesentlich modifiziert worden.

\section{RECTIFICATION}

We regret that on page 198 of Vol. III (1958), Part 2, of this journal an unfortunate misprint has occurred.

Line is should read:

Luxemburgs - ein Brief Kautskys an Lenin, der gleichfalls im Zusam-

1 Dazu Richard W. Reichard: The German Working Class and the Russian Revolution of 1905, in: Journal of Central European Affairs Vol. XIII (1953/54) S. 136-53. 